\title{
Prevalence of bacterial nosocomial infections in matibabu foundation hospital and ukwala sub county referral hospital in Siaya County
}

\begin{abstract}
Nosocomial infection is an infection that is contracted from the environment or staff of a healthcare facility. This infection can transmitted to a susceptible patient in a clinical setting by a number of medium including contaminated equipment, bed linens, or air droplets. This cross sectional study was carried out from March 2015 to August 2015 in Ukwala Sub County Hospital and Matibabu Foundation Hospital in Ugenya Sub county to determine prevalence of Bacterial nosocomial infections in the two Hospitals. A sample size of 108 was used for collection of data. The overall percentage prevalence of nosocomial infection in the two hospitals was found to be twelve point zero three percent $(12.03 \%)$ with USCH recording five point six percent (5.6\%) while MFK had six point five percent $(6.5 \%)$. The most common nosocomial infection was urinary tract infection at nine point zero percent $(9.0 \%)$, followed by Blood stream infection at four percent (4\%).To determine the susceptibility pattern, Modified NCCLS KirbyBauer disc diffusion technique was used and the interpretation of zones done by use of NCCLS chart (Monica Cheesbrough page 141). It is recommended that another study incorporating bacterial, fungal and viral Nosocomial infection be carried out in order to establish the actual prevalence of nosocomial infection in the two hospitals.
\end{abstract}

Keywords: bacterial nosocomial infection, urinary tract infection, primary bacteremia, catheter-related infection
Volume 2 Issue 5 - 2016

Lucy Amanya Mutuli, Miriam Wepukhulu, Cecilia Mwani, Peter Bukhala

Msinde Muliro University of Science and Technology, Kenya

Correspondence: Lucy Amanya Mutuli, Msinde Muliro University of Science and Technology (MMUST), 190-50100, Kenya,Tel +25472 I44 I I83, Email amanyalucy@yahoo.com

Received: September 21, 2016 | Published: October 27, 2016
Abbreviations: WHO, world health organization; UTI, urinary tract infection; CDC, centre for disease control

\section{Introduction}

Infection control and health care associated infections prevalence reports from developing countries are often not well established because of lack of enough staffs and resources. In the United States, the number of HCAI rose from 72 to 98 per cent from 1975 to $1995 .{ }^{1,2}$ The Centre for disease control (CDC) estimates that nearly 2 million patients around the same time in USA were infected with HCAI and the cost of treatment was estimated at 4.5 million dollars per year (WHO, 2002). According to WHO publication, in developing countries the prevalence of HCAI in 2009 varied from $3.8 \%$ to $18.6 \%$. In Kenya, a study conducted in Kenyatta National Hospital on the incidence of catheter associated urinary tract infection (UTI) in the intensive care unit (ICU), established the incidence rate to be $18 \%$ (WHO, 2009). Epidemiological characteristics of nosocomial infections show variations in different hospitals of the same countries..$^{3-5}$ Many of the infections are associated with microorganisms that are resistant to multiple antibiotics and can easily spread on hands of personnel. ${ }^{6}$ Nowadays, over 1.4 million people worldwide and more so in resource limited nations, suffer from infectious complications acquired in hospital. ${ }^{7,8}$ These infections are associated with overstay in hospital, multiple complication, stress to relatives and even loss of lives. ${ }^{9-11}$

\section{Objective}

This study aimed at determining the prevalence rates of nosocomial infections in Matibabu Foundation Hospital (MFK) and Ukwala Sub county Hospital (USCH) in Kenya. ${ }^{12,13}$

\section{Methods}

This was a cross sectional study which was carried out in the two hospitals from May 2015 to August2015. The study was conducted in Siaya County which is one of the counties in the former Nyanza Province in the southwest part of Kenya. It is bordered by Busia County to the north, Kakamega County and Vihiga County's to the northeast and Kisumu County to the southeast. It had a population of 108,934 with ukwala having a population of 49,802 and the urban population in ukwala town where the two hospitals are located being 671(National, 2009). The study was carried out in ukwala town. The focus areas were the two hospitals located in ukwala i.e. Matibabu foundation hospital and Ukwala Sub county Referral hospital. The Inclusion criteria involved: Patients who developed signs of urinary tract infection (UTI), primary bacteremia, catheter-related infection, or wound infection (i.e. at least $48 \mathrm{~h}$ to $72 \mathrm{~h}$ after admission) were eligible and were included in study. Those who qualify were asked for consent to be formally included in the study. Ethical clearance was sought from relevant regulatory bodies.

\section{Data collection procedures}

Data was collected using a predesigned tool which captured both the independent and dependent variables.

\section{Urine specimens culture procedures}

Urine samples were collected for bacteriological examination by the midstream method or catheterization into sterilized container after using catheter. Then the following procedures were carried out;

Biochemical tests: Biochemical tests used in identification of 
the isolates were Catalase test, coagulase test, indole production, Hydrogen gas production, motility test, urease test, oxidase test.

\section{Microbiological susceptibility testing and preparation of turbidity standard}

The antimicrobial susceptibility test was performed using the Kirby Bauer disk diffusion technique. Mueller Hinton agar was prepared and sterilized as instructed by the manufacturer and then poured into $90 \mathrm{ml}$ diameter sterile petri dish to a depth of $4 \mathrm{~mm}$ and kept at $2-8^{\circ} \mathrm{C}$ in sealed plastic bags. For use, the plates were dried at $37^{\circ} \mathrm{C}$ for about 30 minutes. Before inoculation into the Mueller Hinton agar, 3-5 well isolated colonies were removed from a pure culture to make a suspension of the test organism. The turbidity of the test suspension was checked against the turbidity of a chemical standard. A swab was used to collect inoculum by careful rotation against the side of the tube and then the surface of the plate was swabbed by rotating followed by application of disc on the inoculated plate. This was then incubated at $37^{\circ} \mathrm{C}$.

\section{Preparation of turbidity standard}

I. Add $99 \mathrm{ml}$ of water to $1 \mathrm{ml}$ concentrated sulphuric acid $(1 \% \mathrm{v} / \mathrm{v}$ conc. $\mathrm{H} 2 \mathrm{SO} 4(\mathrm{aq})$ ).

Table I Summary of blood culture procedures
II. For $1 \%$ solution of barium chloride, dissolve $0.5 \mathrm{~g}$ of dehydrate barium chloride in $50 \mathrm{ml}$ distilled water.

III. Add $0.6 \mathrm{ml}$ of barium chloride solution to $99.4 \mathrm{ml}$ of sulphuric acid solution and mix.

IV. Store in a well-sealed container in a dark bottle at $20-28^{\circ} \mathrm{C}$.

The drugs for disk diffusion testing were in the following concentrations:

\section{Patterns of nosocomial infections}

Among 108 patients, $13(12.04 \%)$ were confirmed to have nosocomial infection. Of the 13 patients $8(61.54 \%)$ were males and $5(38.46 \%)$ females. The overall distributions of the nosocomial infections in both hospitals were UTIs $9(8.3 \%)$, and BSIs $4(3.7 \%) .{ }^{14}$

\section{Antibiotic usage}

All of the patients included in the study had received antibiotic(s), in the form of either prophylactic or therapeutic (Tables 1-7).

\section{Gram positive bacteria}

Table 8: Percentage susceptibility patterns of S. aureus

\section{Day I}

Using aseptic technique dispense:

Collect blood and inoculate culture media

$0-12 \mathrm{ml}$ blood into Columbia agar diphasic medium and mix incubate up to 7 days

When aerobic infection is suspected, dispense $5 \mathrm{ml}$ blood into thioglycollate broth and mix. Incubate up to 14 days

Dispense $2 \mathrm{ml}$ blood into EDTA and mix

Prepare buffy coat smears from EDTA blood ;

Examine microscopically Gram smear

Gram stain

Day 2

\section{After overnight incubation:}

Examine and report cultures

I. Examine diphasic culture: subculture (even when no growth is seen); in Blood agar and macConkey agar, incubate aerobically, in chocolate agar, incubate in $\mathrm{CO} 2$

Perform antimicrobial susceptibility tests

Table 2 Summary of urine culture procedures

\begin{tabular}{|c|c|c|}
\hline Day I & & \\
\hline Describe appearance & Describe color whether clear or cloudy & \\
\hline $\begin{array}{l}\text { Examine } \\
\text { microscopically }\end{array}$ & $\begin{array}{l}\text { Wet preparation and report:WBCs, RBCs, Casts, } \\
\text { Cells etc }\end{array}$ & $\begin{array}{l}\text { Gram smear : when Bacteria or WBCs (pus cells) are seen in } \\
\text { wet preparation }\end{array}$ \\
\hline Tests Biochemically & Tests to help diagnose UTI & Glucose ,ketones, bilirubin urobilinogen \\
\hline Culture specimen & $\begin{array}{l}\text { CLED agar; inoculate CLED medium and incubate } \\
\text { aerobically }\end{array}$ & \\
\hline \multicolumn{3}{|l|}{ Day 2} \\
\hline $\begin{array}{l}\text { Examine and report } \\
\text { cultures }\end{array}$ & $\begin{array}{l}\text { CLED culture } \\
\text { Look particularly for; } E \text { coli, Proteus, p. aeruginosa, } \\
\text { S. aureus, S. saprophyticus }\end{array}$ & Carry out susceptibility testing as indicated \\
\hline
\end{tabular}


Table 3 Summary of pus culture procedures

\begin{tabular}{ll}
\hline Day I & \\
\hline $\begin{array}{l}\text { Cleanse skin around wound with alcohol and aspirate or } \\
\text { tissue is best }\end{array}$ & $\begin{array}{l}\text { Inoculate on blood and mac conkey agar, Gram } \\
\text { stain }\end{array}$ \\
\hline Day 2 Onwards & $\begin{array}{l}\text { Incubate up to } \\
\text { dioxide }\end{array}$ \\
\hline Identify and perform susceptibility on growths & $\begin{array}{l}\text { When two or more pathogens present report } \\
\text { as mixed flora }\end{array}$
\end{tabular}

Table 4 Himedia discs used on Gram negative bacteria

\begin{tabular}{lll}
\hline Antibiotic & Symbol & Concentration \\
\hline Ampicillin & AMP & $25 \mathrm{mcg}$ \\
Tetracycline & TE & $25 \mathrm{mcg}$ \\
Co-trimoxazole & COT & $25 \mathrm{mcg}$ \\
Streptomycin & S & $10 \mathrm{mcg}$ \\
Kanamycin & K & $30 \mathrm{mcg}$ \\
Gentamycin & GEN & $10 \mathrm{mcg}$ \\
Sulphamethoxazole & SX & $200 \mathrm{mcg}$ \\
Chloramphenicol & C & $30 \mathrm{mcg}$ \\
Nalidixic acid & NA & $30 \mathrm{mcg}$
\end{tabular}

Table 5 Himedia sensitivity Octodiscs KGL 1/4 used on Gram positive bacteria

\begin{tabular}{lll}
\hline Antibiotic & Symbol & Concentration \\
\hline Penicillin-G & $\mathrm{P}$ & $\mathrm{IIU}$ \\
Minocycline & $\mathrm{MI}$ & $30 \mathrm{mcg}$ \\
Erythromycin & $\mathrm{E}$ & $15 \mathrm{mcg}$ \\
Methicillin & MET & $5 \mathrm{mcg}$ \\
Co-trimoxazole & COT & $25 \mathrm{mcg}$ \\
Chloramphenicol & C & $30 \mathrm{mcg}$ \\
Ampicillin & AMP & $10 \mathrm{mcg}$ \\
Lincomycin & L & $2 \mathrm{mcg}$ \\
\hline
\end{tabular}

Table 6 Age and sex distribution of patients investigated for bacterial nosocomial infections

\begin{tabular}{llll}
\hline Age group & Female no $\%$ & Male no \% & Total no \% \\
\hline$<25$ & $12(11.11 \%)$ & $12(11.11 \%)$ & $24(22.22 \%)$ \\
$26-35$ & $10(9.2 \%)$ & $19(17.59 \%)$ & $29(26.85 \%)$ \\
$36-45$ & $14(12.96 \%)$ & $7(7.0 \%)$ & $21(19.44 \%)$ \\
$46-55$ & $3(2.78 \%)$ & $7(7.0 \%)$ & $10(9.26 \%)$ \\
$56-65$ & $4(3.7 \%)$ & $10(9.26 \%)$ & $14(12.96 \%)$ \\
$>66$ & $4(3.7 \%)$ & $6(5.56 \%)$ & $10(9.26 \%)$ \\
TOTAL & $47(43.52 \%)$ & $61(56.48 \%)$ & $108(100 \%)$ \\
\hline
\end{tabular}

Table 7 Distribution of nosocomial infections in the two facilities

\begin{tabular}{llll}
\hline Infection & UTIs & BSIs & Prevalence \% \\
\hline MFK & $3.70 \%$ & $2.80 \%$ & $6.48 \%$ \\
USCH & $4.60 \%$ & $0.93 \%$ & $5.56 \%$ \\
TOTAL & $8.30 \%$ & $3.73 \%$ & $12.04 \%$ \\
\hline
\end{tabular}

Gram positive bacteria

Table 8 Percentage susceptibility patterns of S. aureus

\begin{tabular}{llll}
\hline $\begin{array}{l}\text { Bacterial } \\
\text { isolate }\end{array}$ & $\begin{array}{l}\text { Percentage response to drugs ofS. aureus } \\
\text { isolates } \mathbf{n = 1 2}\end{array}$ & Resistant \\
\hline Drugs & Sensitive & Intermediate & $2(25 \%)$ \\
\hline P & $8(66.7 \%)$ & $2(25 \%)$ & $5(65.5 \%)$ \\
MI & $6(75 \%)$ & $\mathrm{I}(12.5 \%)$ & $2(25 \%)$ \\
E & $5(65.5 \%)$ & $5(65.5 \%)$ & $4(50 \%)$ \\
MET & $7(87.5 \%)$ & $\mathrm{I}(12.5 \%)$ & $3(37.5 \%)$ \\
COT & $2(66.7 \%)$ & $7(87.5 \%)$ & $\mathrm{I}(12.5 \%$ \\
C & $7(87.5 \%)$ & $4(50 \%)$ & $4(50 \%)$ \\
AMP & $6(75 \%)$ & $2(25 \%)$ & $4(50 \%)$ \\
L & $5(65.5 \%)$ & $3(37.5 \%)$ & $\mathrm{I}(12.5 \%)$ \\
TE & $8(66.7 \%)$ & $3(37.5 \%)$ & $3(37.5 \%)$ \\
NA & $5(65.5 \%)$ & $4(50 \%)$ &
\end{tabular}

Gram positive bacteria

\section{Discussion}

From the results obtained, the overall prevalence of nosocomial infections in both hospitals was $12.037 \%$, this was slightly lower than what was expected (5.1-11.6\%) but within the range of WHO in 2009 (3.8-18.6\%) of HCAIs in developing countries. This slight decrease in prevalence in both hospitals may be because of improvement in infection prevention practices, lower infection rate, and availability of high number of health personnel and set up of hospital. ${ }^{15,16}$ This study found lower prevalence of nosocomial infection as compared to ${ }^{17}$ which reported $13 \%$. This lower prevalence may be due to the method of sample analysis, which was dependent mainly on bacteriological agents. Viral and fungal agents were not assessed due to unavailability of technology and laboratory facilities in this study, even though they can cause nosocomial infections. In this study UTI, was the most common nosocomial infection found. Since all of the patients infected had urinary catheters, this then suggests that there is a direct link between catheter use and UTI. The most probable reason could be 
not observing sanitary precautions when inserting the catheter. ${ }^{18}$ The other type infection identified was the blood stream infection which accounted for $3.04 \%$. Two of the cases were for children less the 10 days old. Their infection could have been brought about by lack of proper hygiene especially taking good care of the umbilical stump. Pus swabs cultured did not grow and the reason could have been daily dressings done on the wounds by the nurses. The other could have been keeping the wounds covered at all times and thus not exposed to microorganisms. ${ }^{19}$

Currently many microorganisms have become resistant to different antimicrobial agents which causes a problem in health care facilities.

Table 9 Susceptibility patterns of Proteus species $n=1$.
The antibiotic susceptibility of this study confirmed the scenario of resistance by pathogens to common antibiotics in use. In this particular study, both gram positive and gram negative bacterial isolates showed high resistance level to Cotrimoxazole, Chloramphenicol, and Gentamicin, those still outstanding were Ampicillin and Lincomycin where all the $S$. aureus isolates were susceptible. The reason as to why some of the antibiotics perform poorly could be because of intense use of these drugs outside the hospital, and many antibiotics are available over the counter for self-medication. ${ }^{18,20-24}$ These problems coupled with the increased chance of cross infection among inpatients, are known to account for circulating resistance strains (Tables $9 \& 10$ ) (Figure 1).

\begin{tabular}{llllllllll}
\hline Drugs & AMP & TE & COT & S & K & GEN & SX & C & NA \\
\hline Susceptibility & S & R & R & I & S & S & R & I & S \\
\hline
\end{tabular}

Gram Negative bacteria

Table I0 Gram negative S. aureus susceptibility patterns $n=1$

\begin{tabular}{llllllllll}
\hline Drugs & AMP & TE & COT & S & K & GEN & SX & C & NA \\
\hline Susceptibility & S & S & I & S & S & S & I & R & S
\end{tabular}

NB/S, sensitive; Il intermediate; $R$, resistant

\section{Distribution of samples analysed}

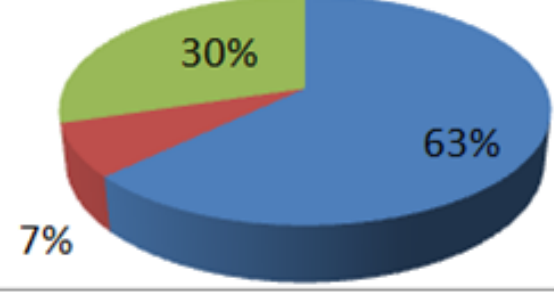

Figure I Distribution of total samples analyzed.

\section{Conclusion}

It was also evident that the isolates showed resistance to more than one type of antibiotics with the leading ones being those commonly bought over the counter.

\section{Acknowledgements}

None.

\section{Conflict of interest}

The author declares no conflict of interest.

\section{References}

1. Bouza E, San Juan R, Munoz P, Voss A, Kluytmans J, et al. A European perspective on nosocomial urinary tract infections II. Report on incidence, clinical characteristics and outcome (ESGNI-004 study). European Study Group on Nosocomial Infection. Clin Microbiol Infect. 2001;7(10):532-542.

2. Mesaros N, Nordmann P, Plésiat P, et al. Pseudomonas aeruginosa: resistance and therapeutic options at the turn of the new millennium. Clin Microbiol Infect. 2007;13(6):560-578.
3. Riddle DJ, Dubberke ER. Clostridium difficile infection in the intensive care unit. Infect Dis Clin North Am. 2009;23(3):727-743.

4. Zilberberg MD, Shorr AF. Preventing clostridium difficile infection in the intensive care unit. Crit Care Clin. 2013;29(1):11-18.

5. Gefand B, Popov T, Kabarak V. Epidemiology and etiology of nosocomial infections in surgical intensive care units. 2005.

6. Durmaz B, Durmaz R, Sonmez E. Nosocomial infections in a New Medical center, Turkey. Infect Control Hosp Epidemiol. 2000;241(8):534-536.

7. Furtado GH, Azevedo PA, Santos AF, et al. Intravenous polymyxin B for the treatment of nosocomial pneumonia caused by multidrug-resistant Pseudomonas aeruginosa. Int J Antimicrob Agents. 2007;30(4):315-319.

8. Jack H. Prevalence of hospital acquired infections in Canadian hospital. 2010 .

9. Herzig SJ, Howell MD, Ngo LH, et al. Acid-suppressive medication use and the risk for hospital-acquired pneumonia. JAMA. 2009;301(20):2120-2128.

10. Cunha BA. Pneumonia Essentials. 3rd ed. USA: Physicians Press; 2010.

11. Jroundi I, Khoudri I, Azzouzi A, et al. Prevalence of hospital acquired infections in a Moroccan university hospital. Am J Infect Control. 2007;35(6):412-416. 
12. MOH. Kenya National Infection prevention guidelines. 2010.

13. Chan RK, Lye WC, Lee EJ, et al. Nosocomial urinary tract infection: a microbiological study. Ann Acad Med Singapore. 1993;22(6):873-877.

14. Agodi A, Barchitta M, Cipresso R, Giaquinta L, Romeo MA, et al. Pseudomonas aeruginosa carriage, colonization, and infection in ICU patients. Intensive Care Med. 2007;33(7):1155-1161.

15. Wang S, Kwok M, McNamara JK, et al. Colistin for Multi-Drug Resistant (MDR) Gram-Negative Bacillary Infections. Antibiotics for Clinicians. 2007;11:389-396.

16. Dridi E, Chetoui A, Zaoui A. Investigation of the prevalence of nosocomial infections in a Tunisian regional hospital. Sante Publique. 2006;18(2):187-194.

17. Ferrara AM. Potentially multidrug-resistant non-fermentative Gramnegative pathogens causing nosocomial pneumonia. Int $J$ Antimicrob Agents. 2006;27(3):183-195.

18. Jones RN. Microbial etiologies of hospital-acquired bacterial pneumonia and ventilator-associated bacterial pneumonia. Clin Infect Dis. 2010;51(Suppl 1):S81-S87.
19. Cunha BA. Multi-drug Resistant (MDR) Klebsiella, Acinetobacter, and Pseudomonas aeruginosa. Antibiotics for Clinicians. 2006;10:354-355.

20. Cheebrough M. Medical Laboratory Manual for Tropical Countries. UK: Cambridg press; 2002

21. Nguyen Q. Hospital acquired infections, medicine from WEBMD medicine. 2004.

22. Shaikh JM, Devrajani BR, Shah SZ, et al. Frequency, pattern and etiology of nosocomial infection in intensive care unit:an experience at a tertiary care hospital. J Ayub Med Coll Abbottabad. 2008;20(4):37-40.

23. Barbut F, Corthier G, Charpak Y, et al. Prevalence and pathogenicity of Clostridium difficile in hospitalized patients. A French multicenter study. Arch Intern Med. 1996;156(13):1449-1454.

24. Bouza E, Torres MV, Radice C, et al. Direct E-test (AB Biodisk) of respiratory samples improves antimicrobial use in ventilator-associated pneumonia. Clin Infect Dis. 2007;44(3):382-387. 